\title{
Adenosine deaminase polymorphism. Associations at clinical level suggest a role in cell functions and immune reactions
}

\author{
E BOTTINI, E CARAPELLA, L CATALDI, M NICOTRA, P LUCARELLI, \\ N LUCARINI, R PASCONE, AND F GLORIA-BOTTINI \\ From the Interdisciplinary Center of Applied Mathematics, Lincei National Academy, Rome; the \\ Department of Genetics, University of Camerino; the Center for Evolutionary Genetics of CNR, Rome; \\ and the Departments of Pediatrics and Child Health, and Obstetrics and Gynecology, State and \\ Catholic Universities of Rome, Rome, Italy
}

SUMMARY It is well known that subjects homozygous for a rare silent allele of ADA may experience a severe combined immunodeficiency. By analogy we have investigated the possible relationship of normal ADA polymorphism with some situations, such as reproductive defects and fetomaternal interactions, in which immunological mechanisms may play an important role. A total of 572 consecutive newborns, 93 consecutive low birthweight infants, 46 couples with unexplained habitual abortion, and 24 couples with unexplained sterility were studied. The proportion of ADA 2-1 phenotype was reduced in couples with reproductive defects. In the sample of consecutive newborns the proportion of ABO incompatible babies was higher among ADA 2-1 than among ADA 1 types. ADA 2-1 phenotype was also associated with a reduction in the variability of gestational length. These associations were much more marked among male than among female babies. The proportion of ADA 2-1 was significantly lower in low birthweight infants than in the consecutively studied infants and normal adults. The present data suggest that biochemical variability resulting from the normal ADA polymorphism may be, at least in part, responsible for the variability of some immunological functions and related physiological variables and pathological conditions. They also provide evidence in favour of a selective advantage of ADA heterozygotes.

It is well known that subjects homozygous for a rare silent allele of adenosine deaminase (ADA:EC 3.5.4.4), and probably also compound heterozygotes, may experience a severe combined immunodeficiency (SCID). ${ }^{1}$ Up to now, however, little attention has been paid to the possible effect that variations of ADA activity, because of the existence of a 'normal' polymorphism, may have on cell functions, immunological reactions, and allied diseases.

The possible relations of ADA polymorphism with reproductive defects and intrauterine development were investigated in the present work. Immunological mechanisms may be important in these situations.

\section{Material and methods}

CONSECUTIVE NEWBORN INFANTS

Two consecutive series of newborn infants from the

Received for publication 16 September 1980 population of Rome were studied. The first series of 357 newborns was collected in the State University and ADA phenotype was determined in the Center for Evolutionary Genetics in Rome. The second series of 215 newborns was collected in the Catholic University and ADA phenotype was determined in the Department of Genetics in Camerino. The results were practically identical.

\section{LOW BIRTHWEIGHT INFANTS}

A prospective sample of 93 low birthweight $(\leq 2.5$ $\mathrm{kg}$ ) singleton babies was also collected from the population of Rome in the Bambino Gesù Hospital for Sick Children. ADA phenotype was determined in the Center for Evolutionary Genetics in Rome.

\section{COUPLES WITH HABITUAL ABORTION OR STERILITY}

From the population of Rome, 46 couples who had had repeated miscarriages (number of consecutive miscarriages $\geqslant 2$ ) were studied. Routine clinical 
investigations, both morphological and functional, were negative.

From the same population, 24 couples with unexplained infertility were also examined. ADA phenotype was determined in the Department of Genetics in Camerino.

\section{CONTROLS}

A sample of normal adults from the population of Rome previously studied by another group ${ }^{2}$ in the Department of Genetics in Rome and the consecutive series of newborn infants described above were considered normal controls for the population of Rome (table 1).

A sample of 487 random adults from the Po Valley, studied in the Center for Evolutionary Genetics in Rome, ${ }^{3}$ are also reported in table 1.

ADA phenotype was determined in all children according to Spencer et al. ${ }^{4}$ ADA 2 phenotype was excluded from $\chi^{2}$ calculations.

Clinical reports on these series of patients and newborns will be submitted elsewhere.

\section{Results}

Table 1 shows the distrit::tion of ADA phenotypes in the series of consecutive newborns and in the two samples of normal adults from the Italian population. ${ }^{23}$ No significant difference is observed between the groups.

Table 2 shows the distribution of ADA types in the series of consecutive infants in relation to $\mathrm{ABO}$

TABLE 1 Percentage distribution of ADA phenotypes in two samples of normal adults and in a series of consecutive newborn infants from the Italian population

\begin{tabular}{|c|c|c|c|c|}
\hline & \multicolumn{3}{|c|}{ ADA phenotype } & \multirow[t]{2}{*}{ No of subjects } \\
\hline & 1 & $2-1$ & 2 & \\
\hline $\begin{array}{ll}\text { Rome } & \begin{array}{l}\text { Adults }^{2} \\
\text { Newborns }\end{array}\end{array}$ & $\begin{array}{l}82 \cdot 50 \\
83 \cdot 57\end{array}$ & $\begin{array}{l}17 \cdot 19 \\
15 \cdot 91\end{array}$ & $\begin{array}{l}0.31 \\
0.52\end{array}$ & $\begin{array}{l}320 \\
572\end{array}$ \\
\hline $\begin{array}{l}\text { Northern } \text { Adults }^{3} \\
\text { Italy }\end{array}$ & $85 \cdot 42$ & $14 \cdot 37$ & 0.21 & 487 \\
\hline Total & 83.97 & $15 \cdot 66$ & 0.36 & 1379 \\
\hline
\end{tabular}

TABLE 2 Percentage distribution of $A D A$ phenotypes among newborn infants in relation to $A B O$ fetomaternal compatibility status

\begin{tabular}{lllll}
\hline & \multicolumn{2}{l}{ ADA phenotype } & $\begin{array}{l}\text { No of } \\
\text { subjects }\end{array}$ \\
\cline { 2 - 4 } & 1 & $2-1$ & 2 & \\
\hline All infants & & & & \\
$\quad \begin{array}{l}\text { Compatible } \\
\text { Incompatible }\end{array}$ & 85.52 & 14.03 & 0.45 & 449 \\
$\begin{array}{l}\text { Males } \\
\text { Compatible }\end{array}$ & 76.42 & 22.76 & $0 \cdot 81$ & 123 \\
Incompatible & 73.91 & 11.44 & 0.85 & 236 \\
$\begin{array}{l}\text { Females } \\
\text { Compatible }\end{array}$ & 83.10 & 16.90 & - & 69 \\
Incompatible & 79.63 & 20.37 & - & 213 \\
\hline
\end{tabular}

fetomaternal compatibility status. Incompatible infants show a higher proportion of ADA 2-1 as compared to compatible newborns. The difference is much more marked among males $(\mathrm{p}<0.01)$.

Table 3 shows the relation between length of gestation and ADA phenotype. ADA 2-1 is associated with a lower variability in length of gestation as compared to ADA 1. This is more evident among males; in these subjects the proportion of preterm and post-term births is much lower among ADA 2-1 than among ADA 1 phenotypes $(0.07$ vs $0 \cdot 16)$.

Table 4 shows the distribution of ADA phenotypes in low birthweight infants. The proportion of ADA $2-1$ is lower than in the controls $(\mathrm{p}<0.05)$. Of these infants, 57 were preterm and 36 small for dates. The proportion of ADA 2-1 was low in both groups. These data seem to confirm the negative association

TABLE 3 Relation between length of gestation and ADA phenotype

\begin{tabular}{|c|c|c|c|c|}
\hline & & \multicolumn{3}{|c|}{$A D A$ phenotype } \\
\hline & & $l$ & $2-1$ & 2 \\
\hline $\begin{array}{l}\text { All infants } \\
\text { Length of gestation } \\
(w k) \\
\text { No of subjects }\end{array}$ & $\begin{array}{l}\text { Mean } \\
\text { SE } \\
\text { Variance }\end{array}$ & $\begin{array}{c}39.59 \\
0.09 \\
3 \cdot 87 \\
474\end{array}$ & $\begin{array}{c}39 \cdot 58 \\
0 \cdot 17 \\
2 \cdot 47 \\
90\end{array}$ & $\begin{array}{r}40 \cdot 67 \\
1 \cdot 36 \\
5 \cdot 55 \\
3\end{array}$ \\
\hline $\begin{array}{l}\text { Males } \\
\text { Length of gestation } \\
(w k) \\
\text { No of subjects }\end{array}$ & $\begin{array}{l}\text { Mean } \\
\text { SE } \\
\text { Variance }\end{array}$ & $\begin{array}{c}39 \cdot 52 \\
0 \cdot 12 \\
3 \cdot 59 \\
256\end{array}$ & $\begin{array}{c}39 \cdot 63 \\
0 \cdot 18 \\
1 \cdot 39 \\
43\end{array}$ & $\begin{array}{r}40 \cdot 67 \\
1 \cdot 36 \\
5 \cdot 55 \\
3\end{array}$ \\
\hline $\begin{array}{l}\begin{array}{l}\text { Females } \\
\text { Length of gestation } \\
(w k)\end{array} \\
\text { No of subjects }\end{array}$ & $\begin{array}{l}\text { Mean } \\
\text { SE } \\
\text { Variance }\end{array}$ & $\begin{array}{c}39 \cdot 69 \\
0 \cdot 14 \\
4 \cdot 17 \\
218\end{array}$ & $\begin{array}{r}39 \cdot 53 \\
0 \cdot 27 \\
3 \cdot 48 \\
47\end{array}$ & $\begin{array}{l}- \\
-\end{array}$ \\
\hline
\end{tabular}

Five subjects were excluded since reliable information on length of gestation was lacking.

TABLE 4 Percentage distribution of ADA phenotype in low birthweight infants

\begin{tabular}{llll}
\hline & \multicolumn{2}{l}{ ADA phenotype } & No of subjects \\
\hline Low birthweight infants & 91.4 & $8-1$ & \\
\hline
\end{tabular}

TABLE 5 Percentage distribution of ADA phenotypes in couples with habitual abortion or sterility from the population of Rome

\begin{tabular}{|c|c|c|c|c|c|}
\hline & & \multicolumn{3}{|c|}{$A D A$ phenotype } & \multirow[t]{2}{*}{ No of subjects } \\
\hline & & 1 & $2-1$ & 2 & \\
\hline Abortion & $\begin{array}{l}\text { Wives } \\
\text { Husbands }\end{array}$ & $\begin{array}{l}93.49 \\
86.96\end{array}$ & $\begin{array}{r}6.52 \\
13.04\end{array}$ & - & $\begin{array}{l}46 \\
46\end{array}$ \\
\hline $\begin{array}{l}\text { Sterility } \\
\text { Total }\end{array}$ & $\begin{array}{l}\text { Wives } \\
\text { Husbands }\end{array}$ & $\begin{array}{r}91 \cdot 67 \\
95 \cdot 83 \\
91 \cdot 43\end{array}$ & $\begin{array}{l}8 \cdot 33 \\
4 \cdot 17 \\
8 \cdot 57\end{array}$ & - & $\begin{array}{r}24 \\
24 \\
140\end{array}$ \\
\hline
\end{tabular}


between ADA 2-1 and preterm delivery observed in the series of consecutive newborns.

Table 5 shows the distribution of ADA phenotype in patients with habitual abortion or sterility. The differences between abortion and sterility and between males and females are not significant. When comparing the whole group of reproductive defects with controls, a reduction of ADA 2-1 is observed among these patients also $(p<0 \cdot 02)$.

\section{Discussion}

The role of the $\mathrm{ABO}$ system in the fetomaternal relationship and intrauterine selection is well known. ${ }^{56}$ Therefore, the interaction between ADA and ABO polymorphisms appears the most interesting observation. The association is highly significant and the results are identical in two samples using data from two different laboratories. Therefore, the possibility of methodological bias can be reasonably excluded.

The association with length of gestation is very suggestive also. Although the level of statistical significance is moderate, the concordance of results between two series of newborns collected by different criteria (consecutive and low birthweight infants) reinforces the validity of inference and argues against possible sampling artefacts.

The association between ADA phenotype and reproductive defects appears rather doubtful. Although not significant in our sample, differences between abortion and sterility and between wives and husbands may indeed exist. More extensive data are necessary in order to clarify the situation and to exclude the possibility of sampling chance phenomena.

In the present context it is interesting to report that in a parallel study of 179 children with bronchial asthma, collected in two different Italian populations, a highly significant reduction of the proportion of ADA 2-1 as compared to controls from the same population was observed. ${ }^{7}$

ADA is a polymorphic enzyme which catalyses the deamination of adenosine to inosine. Its synthesis is controlled by an autosomal locus with two codominant alleles $\mathrm{ADA}^{1}$ and $\mathrm{ADA}^{2}$. The enzymatic activity of heterozygous $\mathrm{ADA}^{1} / \mathrm{ADA}^{2}$ is lower than that of homozygous $\mathrm{ADA}^{1} / \mathrm{ADA}^{1}{ }^{1}{ }^{8}$

Inhibition of ADA activity reduces DNA synthesis through a raised intracellular adenosine concentration. When deamination is blocked, the major route of adenosine nucleosides metabolism in mammalian cells involves their conversion to $5^{\prime}$ nucleotides. Most of the toxic effects of nucleosides are generally attributed to their nucleotide derivatives. Conversion of adenosine to intracellular nucleotides results in the inhibition of de novo synthesis of pirimidine. DeoxyATP derived from 2-deoxyadenosine is an inhibitor of ribonucleoside diphosphate reductase. $^{9-11}$ The lack of nucleic acid synthesis would cause lymphopenia in patients with SCID. ${ }^{12} 13$ Recently, it has been suggested that an increased concentration of deoxyadenosine leads to inactivation of S-adenosylhomocysteine hydrolase, accumulation of S-adenosylhomocysteine, and depletion of cellular S-adenosylmethionine. This would prevent essential methylation reactions. ${ }^{14}$ The expansion of the intracellular pool of adenosine may also inhibit the cellular response to various stimuli through an increase of cAMP level ${ }^{15}$ (figure).

Studies on the relations between ADA and immunity should not be restricted to (monofactorial) pathological conditions resulting from extreme enzyme deficiency associated with rare ADA variants. We suggest that variability owing to ADA polymorphism may have an important effect on cell functions, and may influence the variability of immunological parameters and the susceptibility to related (multifactorial) pathological conditions.

The possible role of ADA polymorphism in the modulation of intracellular concentration of cAMP should be investigated. A slight decrease of ADA activity could be associated with higher cAMP levels which in turn may increase the threshold for a

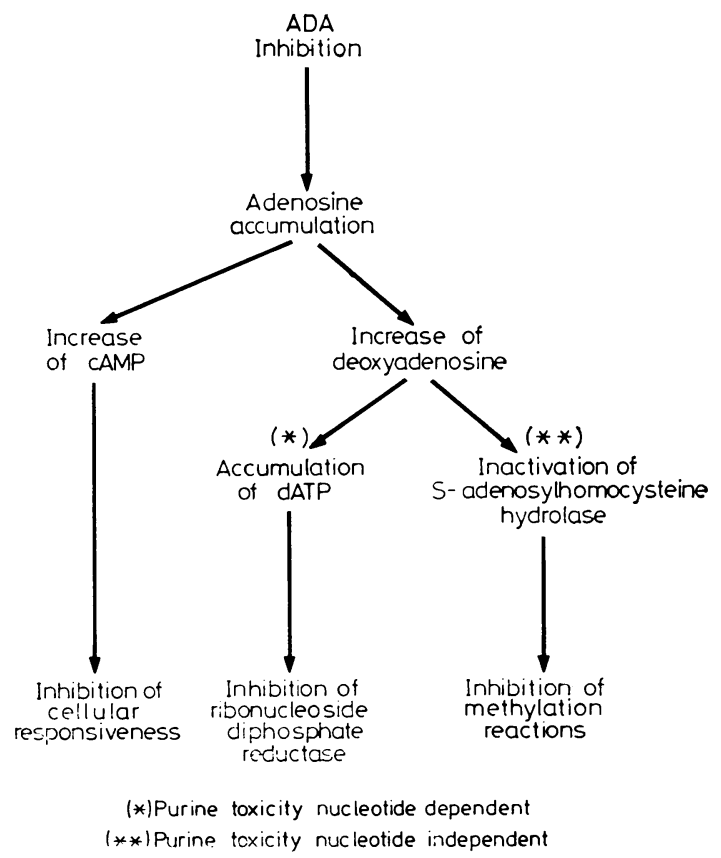

FIGURE Some possible consequences of adenosine deaminase inhibition. 
cellular response of clinical relevance (asthma, premature rejection of zygote). Concerning allergy, for example, it has been recently reported that adenosine is able to impair basophil histamine release through an increase of cAMP level. ${ }^{16} \mathrm{~A}$ reduced immunological response may also be mediated by a decreased DNA synthesis in subjects of ADA 2-1 phenotype. The analysis of more specific immunological functions both in vivo and in vitro in relation to ADA phenotype may help to clarify some of these problems. Should our conjectures be correct, one would expect, for example, a more rapid and intense response to vaccinations in ADA 1 than in ADA 2-1 subjects.

Lymphocytes and immunological functions, however, may not necessarily be involved in the phenomena reported here. A slightly higher mean cellular level of cAMP in ADA 2-1 phenotype may contribute to decreasing the susceptibility of large cellular systems at bronchial or placental level to an abnormal response. The incidence of clinical manifestations would therefore be reduced in these subjects.

Adenosine and several of its analogues inhibit the growth of cultured mammalian cells and in some cases viral replication. The effects are enhanced by drugs which inhibit adenosine deaminase activity. ${ }^{14}$ It is known that some arabinoside analogues of adenosine have both cytostatic and antiviral activities. Their use in conjunction with inhibitors of deaminase have been proposed as a means of increasing their potency. ${ }^{14}$ These facts may suggest some other lines of investigation concerning the mechanism of the described associations.

The data reported here seem to give some support to our speculations and call for further research in this area.

Perinatal selection is stabilising on gestational age and birthweight: that is, both minus and plus variants have a reduced probability of survival. The data on consecutive and low birthweight infants indicate that heterozygous ADA 2-1 newborns may be the fittest as regards perinatal selection. The interaction with the $\mathrm{ABO}$ system and the observations on bronchial asthma and reproductive disorders also suggest a heterozygous advantage and indicate a possible mechanism for the maintenance of ADA polymorphism.

This work was supported by CNR.
References

1 Hirschorn R. Adenosine deaminase deficiency and immunodeficiencies. Fed Proc 1977;36:2166-70.

2 Scozzari R, Santolamazza C, Carapella E. Studies on the red cell adenosine deaminase polymorphism in Rome. Humangenetik 1970;8:364-6.

3 Lucarelli P, Corbo RM, Scacchi R, et al. A study of nine polymorphic systems in the population of the Po Delta. Am J Phys Anthropol 1976;45:211-6.

4 Spencer N, Hopkinson D, Harris H. Adenosine deaminase polymorphism in man. Ann Hum Genet 1968;32:9-14.

5 Cohen BH. ABO and Rh incompatibility. I. Fetal and $\sigma$ neonatal mortality with $\mathrm{ABO}$ and $\mathrm{Rh}$ incompatibility: some new interpretations. Am J Hum Genet 1970;22: ৫ै 412-40.

- Takano K, Miller JR. ABO incompatibility as a cause of spontaneous abortion: evidence from abortuses. $J$ Med Genet 1972;9:144-50.

7 Bottini E, Ronchetti R, Lucarini N, et ai. Unpublished observations, 1980.

8 Battistuzzi G, Scozzari R, Santolamazza P, Terrenato L, Modiano G. Comparative activity of red cell adenosine deaminase allelic forms. Nature $1974 ; 251$ :711-2.

9 Donofrio J, Coleman MS, Hutton JJ, Daoud A, Lampkin B, Dyminski J. Overproduction of adenine deoxynucleo- $\frac{\mathbb{}}{-}$ sides and deoxynucleotides in adenosine deaminase $\vec{c}$ deficiency with severe combined immunodeficiency $œ$ disease. J Clin Invest 1978;62:884-7.

10 Mitchell BS, Mejias E, Daddona PE, Kelley WN. Purinogenic immunodeficiency diseases: selective toxicity of deoxyribonucleosides for T cells. Proc Natl Acad Sci USA 1978;75:5011-4.

11 Wilson JM, Mitchell BS, Daddona PE, Kelley WN. Differential effects of deoxyadenosine and deoxyguanosine on DNA synthesis in human $\mathrm{T}$ lymphoblasts. $J$ Clin Invest $1979 ; 64: 1475-84$.

12 Editorial. ADA deficiency. Lancet 1976;i:895-6.

13 Rosen FS. Enzyme defects and immune dysfunction. Nature 1978;276:559-60.

14 Hershfield MS. Apparent suicide inactivation of human lymphoblast S-adenosylhomocysteine hydrolase by $2^{\prime}-\bar{c}$ deoxyadenosine and adenine arabinoside: a basis for $\dot{ }$ direct toxic effects of analogs of adenosine. J Biol Chem $1979 ; 254: 22-5$.

15 Wolberg G, Zimmerman TP, Hiemstra K, Winston M, Chu LC. Adenosine inhibition of lymphocyte-mediated cytolysis: possible role of cyclic adenosine mono- 음 phosphate. Science 1975;187:957-9.

16 Marone G, Lichtenstein LM. Adenosine-adenosine $\frac{D}{O}$ deaminase modulation of histamine release from human basophils in vitro. Ric Clin Lab 1979;9:131-7.

Requests for reprints to Dr E Bottini, Accademia Nazionale dei Lincei, Via della Lungara 10, 00165 Roma, Italy. 